\title{
What Is the Return on Investment of Caring for Complex High-need, High-cost Patients?
}

\author{
Evelyn T. Chang, MD, MSHS ${ }^{1,2,3}$ (D), Steven M. Asch, MD, MPH ${ }^{4,5}$, Jessica Eng, MD ${ }^{6,7}$, \\ Frances Gutierrez, $R N^{8}$, Angela Denietolis, $M D^{9}$, and David Atkins, $M D, M P H^{10}$
}

'VA Center for the Study of Healthcare Innovation, Implementation and Policy (CSHIIP), Los Angeles, CA, USA; ${ }^{2}$ Department of General Internal Medicine, VA Greater Los Angeles Healthcare System, Los Angeles, CA, USA; ${ }^{3}$ Division of General Internal Medicine, Geffen School of Medicine, University of California at Los Angeles, Los Angeles, CA, USA; ${ }^{4}$ VA HSR\&D Center for Innovation to Implementation, Menlo Park, CA, USA; 5 Division of Primary Care and Population Health, Stanford University School of Medicine, Palo Alto, CA, USA; 'VA San Francisco Healthcare System, San Francisco, CA, USA; ${ }^{7}$ University of California San Francisco, School of Medicine, San Francisco, CA, USA; ${ }^{8}$ Clement J. Zablocki VA Medical Center, Milwaukee, WI, USA; ${ }^{9}$ VA Office of Primary Care, Washington, DC, USA; ${ }^{10}$ VA Health Services Research and Development, Washington, DC, USA.

Randomized controlled trials to improve care for complex, high-need, high-cost patients have not consistently demonstrated a relative decrease in acute care utilization or cost savings. However, the Veterans Health Administration (VHA) has been able to glean lessons from these trials and generate realistic expectations for success. Lessons include the following: (1) combining population management tools (e.g., risk scores) and clinician judgment is more effective than either alone to identify the patients best suited for intensive management; (2) treatment adherence and engagement may contribute more to preventable emergency department visits and hospitalizations than care coordination; and (3) efforts should focus on assessing for and treating those risk factors that are most amenable to intervention. Because it is unlikely that cost savings can fund add-on intensive management programs, the VHA Office of Primary Care plans to incorporate those intensive management practices that are feasible into existing patient-centered medical homes as a high reliability organization.

$\mathrm{J}$ Gen Intern Med 36(11):3541-4

DOI: $10.1007 /$ s11606-021-07110-y

This is a U.S. government work and not under copyright protection in the U.S.; foreign copyright protection may apply 2021

$\mathrm{C}$ omplex high-need patients are costly to healthcare systems ${ }^{1-3}$ and at high risk for adverse outcomes, including hospitalizations and uncoordinated care. ${ }^{1}$ Thus, many assumed they represented a good target for interventions that would both reduce costs and improve outcomes. While many studies have reported promising interventions, few have been rigorously tested. Those tested through randomized controlled trials, such as those conducted at the Veterans Health Administration (VHA) ${ }^{4-6}$ and in non-VHA settings, ${ }^{7-9}$ have shown that neither the care of caring for complex, high-need patients

Received February 11, 2021

Accepted August 20, 2021

Published online September 10, 2021 nor the business case for improving that care, is straightforward. Reasons include the heterogeneity of this population, the complexity of the intervention, and the limited outcomes that are often studied. ${ }^{7}$ What can we learn from these interventions, even if they did not succeed in reducing costs?

Since 2013, the VHA has invested over \$22 million in fostering and testing interventions within patient-centered medical homes at five demonstration sites to improve care for patients at the highest risk for hospitalizations or death. We observed that most high-risk patients are cared for in general primary care rather than in other specialized primary care settings ${ }^{10}$ and that half of primary care providers and nurses feel that caring for highrisk patients is the most stressful aspect of their job. ${ }^{11}$ Thus far, our randomized quality improvement evaluation of VHA intensive management teams has demonstrated increased patient engagement, ${ }^{12}$ improved patient trust, ${ }^{13}$ and greater support to primary care teams. ${ }^{11}$ While the VHA did not observe cost reductions, the improved outcomes came at no greater cost to the healthcare system compared to patient-centered medical homes, even after accounting for program costs. ${ }^{6}$

The VHA Primary Care intensive management teams ${ }^{14}$ were similar to other comprehensive case management teams described in the literature. ${ }^{7,8,15}$ The teams included a physician lead (trained in internal medicine), social workers, nurses, psychologist, and in some instances, a peer support specialist. The entire team was trained in patient-centered care principles and motivational interviewing. Similar to other programs, they performed an interdisciplinary assessment of the patient's needs (in the home if possible) and assisted the patient and the primary care team with care coordination, health education and navigation, medication management, community resources, and advanced care planning. They also used "co-attends," where a member of the team attended a patient's encounter with a specialist to assist with care coordination between providers and facilitate treatment plan implementation. Over time, the team developed trusting relationships with the patients to influence their health behaviors.

The VHA intensive management teams also tailored their intervention to patient and system needs. The teams developed a repertoire of services, ranging from "low-touch" electronic 
consults (e.g., providing recommendations to primary care or referring to other VHA or community resources) to providing "high-touch" case management.

During this journey, the VHA has learned important lessons that have been used to inform future directions. These lessons are likely applicable to non-VHA settings that offer alternative payment models, such as other integrated delivery systems, accountable care organizations ${ }^{16}$, and advanced primary care medical homes ${ }^{17}$.

\section{LESSON \# 1: USING A COMBINATION OF POPULATION MANAGEMENT AND CLINICIAN JUDGMENT IS VALUABLE FOR IDENTIFYING THE PATIENTS BEST SUITED FOR INTENSIVE MANAGEMENT}

As part of this initiative, VHA tried two different models of identifying patients. For the first phase, we used a validated VHA risk algorithm ${ }^{18}$ to identify the patients at the highest risk for hospitalization and/or death based on clinical administrative data (e.g., utilization, diagnoses, lab values). Our demonstration sites then reviewed high-risk patient charts $(n=1901)$ and selected the ones that were the best fit for the program. ${ }^{19}$ Based on their clinical judgment, teams felt that some $15 \%(n=286 / 1901)$ of these patients would not likely benefit from intensive case management due: to absence of an ambulatory care-sensitive condition $(n=80)$; having a severe mental health disorder or substance use disorder $(n=51)$; moving away $(n=40)$; living outside eligibility area for home visits $(n=35)$; having other case management services or in a nursing home $(n=25)$; being more appropriate for another VHA case management program (i.e., homeless primary care $\left.{ }^{20}\right)(n=16)$; already receiving recommended care in primary or specialty care $(n=9)$; or other reasons $(n=30)$. Primary care providers felt that $16 \%(n=303 / 1901)$ of the patients did not need intensive case management. Over a quarter of the high-risk patients declined intensive case management services $(28 \% ; n=541 /$ 1901) because they did not perceive a need for them or were not interested. Overall, only 38\% ( $n=726 / 1901)$ of high-risk patients eventually received intensive case management services, similar to other non-VA settings. ${ }^{21}$

During the second phase, the demonstration sites accepted referrals that met eligibility criteria (i.e., high-risk score). We found that the proportion of patients engaged by the program from referrals was higher $(73 \% ; 263 / 364)$ than that of patients who were identified through administrative data alone (38\%). However, the number of referred patients was smaller than anticipated. To bolster the numbers, some demonstration sites ended up reviewing lists of patients with high-risk scores to identify potential participants. One demonstration site leader observed that solely relying upon referrals may miss patients who are not well established in primary care or if primary care teams are not adept at panel management.

In the future, VHA ability to use administrative data to predict which patients benefit most from case management may improve once social determinants of health (e.g., functional status, cognitive impairment, caregiver status, social support) are part of the routine electronic health record. For now, we believe the referral and population-based management approaches are complementary and should be combined to identify patients.

\section{LESSON \#2: TOP REASONS FOR PREVENTABLE EMERGENCY DEPARTMENT (ED) VISITS AND HOSPI- TALIZATIONS WERE NOT DUE TO UNCOORDINATED CARE}

In literature, lack of post-discharge follow-up and poor care coordination during transitions in care are cited as among the most common contributors to readmissions. ${ }^{22-24}$ Perhaps because the VHA is an integrated system, providers did not find poor coordination to be the most important factor. Instead, non-adherence, lack of engagement (defined here as a patient's participation in self-care and other health-related activities, motivation and ability to address health issues, and shared decision-making ${ }^{25-27}$ ) and behavioral health issues dominated.

The VHA interdisciplinary intensive management teams routinely assessed potential reasons for preventable ED visits and hospitalizations. The most common reasons were as follows: (1) inadequate engagement, as demonstrated by no-shows ${ }^{28}$ and lack of response to healthcare staff phone calls, with ambulatory care (Primary Care, Mental Health, Specialty care) $(n=48 / 262 ; 18 \%)$, (2) medication non-adherence $(n=45 / 262 ; 17 \%)$, (3) treatment adherence (diet, appointments) ( $n=31 / 262 ; 12 \%)$, (4) active alcohol or substance use $(n=29 / 262 ; 11 \%)$, and (5) poor health literacy or insufficient education on health issues and the appropriate use of ER ( $n=26 / 262 ; 10 \%)$.

To address these problems, intensive management teams spent considerable effort to build trusting relationships with patients through frequent outreach, responding quickly to patient phone calls and requests, building rapport, extensive coaching and education, and performing home visits ${ }^{12,27}$. In addition, they assessed for reasons underlying medication and treatment non-adherence and educated patients on appropriate emergency department use. Peer support specialists were particularly helpful to engage patients, to improve health literacy, and to help with managing expectations. As a result, patients who received intensive management services reported improved quality of care and behavior changes, such as increased medication adherence and eating a healthy diet. ${ }^{12,29}$

\section{LESSON \#3: INTENSIVE MANAGEMENT EFFORTS SHOULD FOCUS ON ASSESSMENT FOR AND TREATMENT OF MODIFIABLE RISK FACTORS AMONG MODERATELY HIGH-RISK PATIENTS}

During the pre-pilot period of the intensive management program, VHA demonstration sites reviewed hundreds of cases to 
determine the eligibility criteria. They found that patients with the highest risk scores may have trajectories that were not modifiable (with exception of palliative care efforts), and in fact, were too sick for intensive outpatient efforts. Instead, they felt that patients with moderately high-risk scores were more suitable candidates.

Ascertaining which patient risk factors might be modifiable has been challenging. ${ }^{30}$ Our demonstration sites learned that there were some risk factors that were more modifiable than others. For instance, social needs, such as social isolation, need for geriatric resources (e.g., adult day health care, inhome supportive services), housing instability, food insufficiency, and problems with health literacy were thought to be modifiable. Issues with existing caregivers, such as unengaged caregivers and caregiver burnout, and identifying a support system unknown to the primary care team were considered modifiable. Mental and/or behavioral needs were also considered modifiable, specifically medication non-adherence or diagnosis of non-compliance, depression, post-traumatic stress disorder, and opioid use disorder, due to availability of evidence-based treatment for each of these conditions. Patients with barriers to in-person visits that could be addressed with transportation, home visits, or virtual home visits were also thought to be modifiable. Understanding which risk factors may be modifiable can allow teams to perform focused assessments once a patient is identified as "high-risk" and implement care pathways for identified needs. As a result, focusing on some of these modifiable factors made involvement of the intensive management teams relatively brief, only 3-6 months, for some patients. As a corollary, there were factors that were thought to be relatively less modifiable, even by intensive outpatient primary care teams. Teams felt that patients who were less ready, lacked interest, or lacked the ability to participate in the intensive management program, often due to severe mental health symptoms, substance use, or cognitive deficits, were more challenging. If the patients themselves were unable to engage with the intensive management team, the team sought family or caregivers who could be engaged. Patients with severe personality disorder, severe substance use disorder (except for opioid use disorder), and chronic suicidality were thought to be better suited for intensive case management by the Mental Health Intensive Case Management (MHICM) team, VHA's Assertive Community Treatment team, led by psychiatrists and with mental health staff. Other patients who were not easily helped included those with cognitive impairment with no caregiver or social support to assist with implementation of the treatment plan. Those with too many competing life demands and therefore unavailable for the team's interventions were also thought to not be good candidates for intensive management. These factors were often not easily identified on chart review but may have been identified only after multiple attempts to engage the patient and by several team members.

\section{CONCLUSION}

The VHA's complex high-need high-cost demonstration was set up as a quality improvement project, which can provide information in a real-world setting, but rigorously studied as a randomized controlled trial. The evaluation has revealed that dramatic improvements in pre-post analyses are probably due to regression to the mean. ${ }^{31}$ Adequately controlled comparisons revealed no significant differences in VHA and nonVHA hospitalizations, costs, ${ }^{5,6}$ or medication adherence. ${ }^{6}$ The VHA has not studied other potential outcomes of intensive case management programs, such as avoidance of early institutionalization and decreases in homelessness or recidivism, which may have societal cost implications, or changes in self-efficacy and overall general health. ${ }^{7}$ The VHA has, however, demonstrated improved patient experiences, particularly trust in VHA providers. ${ }^{13}$ While improving trust in VHA may not directly lead to cost savings, it may provide other intangible benefits to patients and to the American public.

High-quality demonstrations, including randomized trials, such as the VHA complex high-risk patient demonstration, show there are no easy solutions to bend the cost curve for these patients. As these intensive management programs do not decrease costs any more than patient-centered medical homes, the VHA Office of Primary Care plans to incorporate those intensive management practices that are feasible into existing patientcentered medical homes. Such practices may include using the "Whole Health" approach ${ }^{32}$ to understand patient goals, values, and preferences; using the entire multidisciplinary team in the medical home ${ }^{33}$ to create a cohesive treatment plan for high-risk patients; and using motivational interviewing to counsel high-risk patients. In fact, high-risk patients have served as a lens to view the strengths and pitfalls of the healthcare system from the perspective of the sickest, most vulnerable patients. The VHA has learned invaluable lessons from this initiative that has reinforced the value of primary care's team-based model of care and will be put forth into the healthcare system as improvements for all patients, further developing as a learning healthcare system. ${ }^{34}$

Acknowledgements: We would like to acknowledge the clinical wisdom of the VHA PACT Intensive Management team members who contributed to these ideas (Angela Bodnar, LCSW, Lachaka Coffee-Meadows, NP, Nate Ewigman, Vickie Jones, RN, PhD, Melissa Klein, MD, Irene Kostiwa, PhD, Jenna Pierce, PhD, and Sudip Roy, MD) and Emily Wong, MPH, who took copious meeting notes.

The views expressed in this article are those of the authors and do not necessarily reflect the position or policy of the Department of Veterans Affairs, or the US government, or other affiliated institutions. The PACT Intensive Management initiative was funded by the VHA Office of Primary Care (Washington DC).

Corresponding Author: Evelyn T. Chang, MD, MSHS; VA Center for the Study of Healthcare Innovation, Implementation and Policy (CSHIIP), Los Angeles, CA, USA (e-mail: evelyn.chang@va.gov). 


\section{Declarations:}

Conflict of Interest: None of the authors have declared any potential conflicting interests.

\section{REFERENCES}

1. Zulman DM, Pal Chee C, Wagner TH, et al. Multimorbidity and healthcare utilisation among high-cost patients in the US Veterans Affairs Health Care System. BMJ Open. 2015;5(4):e007771. doi:https:// doi.org/10.1136/bmjopen-2015-007771

2. Stanton M, Rutherford M. The High Concentration of US Health Care Expenditures. 2005. Research in Action Issue 19.

3. Cohen SB, Yu W. The Concentration and Persistence in the Level of Health Expenditures over Time: Estimates for the U.S. Population, 2008-2009. 2012. Statistical Brief \#354.

4. Zulman DM, Pal Chee C, Ezeji-Okoye SC, et al. Effect of an Intensive Outpatient Program to Augment Primary Care for High-Need Veterans Affairs Patients: A Randomized Clinical Trial. JAMA Intern Med. 2017;177 (2): 166-175. doi:https://doi.org/10.1001/jamainternmed.2016.8021

5. Wong ES, Guo R, Yoon J, et al. Impact of VHA's primary care intensive management program on dual system use. Healthc (Amst). Sep 2020;8 (3): 100450. doi:https://doi.org/10.1016/j.hjdsi.2020.100450

6. Yoon J, Chang E, Rubenstein LV, et al. Impact of Primary Care Intensive Management on High-Risk Veterans' Costs and Utilization: A Randomized Quality Improvement Trial. Ann Intern Med. 2018;168 (12):846-854. doi:https://doi.org/10.7326/M17-3039

7. Finkelstein A, Zhou A, Taubman S, Doyle J. Health Care Hotspotting A Randomized, Controlled Trial. $N$ Engl $J$ Med. 2020;382(2):152-162. doi: https://doi.org/10.1056/NEJMsa1906848

8. Balaban RB, Galbraith AA, Burns ME, Vialle-Valentin CE, Larochelle MR, Ross-Degnan D. A Patient Navigator Intervention to Reduce Hospital Readmissions among High-Risk Safety-Net Patients: A Randomized Controlled Trial. J Gen Intern Med. 2015;30(7):907-15. doi:https://doi. org/10.1007/s11606-015-3185-x

9. Englander H, Michaels $\mathbf{L}$, Chan B, Kansagara D. The care transitions innovation (C-TraIn) for socioeconomically disadvantaged adults: results of a cluster randomized controlled trial. J Gen Intern Med. 2014;29 (11): 1460-7. doi:https://doi.org/10.1007/s11606-014-2903-0

10. Chang ET, Zulman DM, Nelson KM, et al. Use of General Primary Care, Specialized Primary Care, and Other Veterans Affairs Services Among High-Risk Veterans. JAMA Netw Open. 2020;3(6):e208120. doi:https:// doi.org/10.1001/jamanetworkopen.2020.8120

11. Okunogbe A, Meredith LS, Chang ET, Simon A, Stockdale SE, Rubenstein LV. Care coordination and provider stress in primary care management of high-risk patients. J Gen Intern Med. 2018;33(1):65-71. doi:https://doi.org/10.1007/s11606-017-4186-8

12. Bergman A, Stockdale S, Katz M, Zulman D, Chang E. Strategies for Short and Long-Term Patient Engagement Among High-Need Patients: Reflections of Key Stakeholders in VA's Primary Care Intensive Management (PIM) Teams. presented at: Academy Health Annual Research Meeting; June 2-4, 2019 Washington, DC

13. Zulman DM, Chang ET, Wong A, et al. Effects of Intensive Primary Care on High-Need Patient Experiences: Survey Findings from a Veterans Affairs Randomized Quality Improvement Trial. $J$ Gen Intern Med. 2019;34(Suppl 1):75-81. doi:https://doi.org/10.1007/ s11606-019-04965-0

14. Chang ET, Raja PV, Stockdale SE, et al. What are the key elements for implementing intensive primary care? A multisite Veterans Health Administration case study. Healthcare. 2018;6(4):231-237. doi: https:// doi.org/10.1016/j.hjdsi.2017.10.001

15. Iovan S, Lantz PM, Allan K, Abir M. Interventions to Decrease Use in Prehospital and Emergency Care Settings Among Super-Utilizers in the United States: A Systematic Review. Medical Care Research and Review. March 28 2019:1-22. doi:https://doi.org/10.1177/1077558719845722

16. Niles $\mathbf{J}$, Litton $\mathbf{T}$, Mechanic $\mathbf{L}$. An Initial Assessment Of Initiatives To Improve Care For High-Need, High-Cost Individuals In Accountable Care Organizations. April 11, 2019, 2019. https://www.healthaffairs.org/do/ 10.1377/hblog20190411.143015/full/

17. Sessums LL, McHugh SJ, Rajkumar R. Medicare's Vision for Advanced Primary Care: New Directions for Care Delivery and Payment. Jama. 2016;315(24):2665-6. doi:https://doi.org/10.1001/jama.2016.4472
18. Wang L, Porter B, Maynard C, et al. Predicting risk of hospitalization or death among patients receiving primary care in the Veterans Health Administration. Med Care. 2013;51(4):368-73. doi:https://doi.org/10. 1097/MLR.0b013e31827da95a

19. Hulen E, Laliberte A, Chang E, et al. Patient Selection Strategies in an Intensive Primary Care Program. Virtual Poster presented at: Academy Health Annual Research Virtual Meeting; June 14-17 2021 2021; Virtual Meeting.

20. O'Toole TP, Johnson EE, Aiello R, Kane V, Pape L. Tailoring Care to Vulnerable Populations by Incorporating Social Determinants of Health: the Veterans Health Administration's "Homeless Patient Aligned Care Team” Program. Prev Chronic Dis. 2016;13:E44. doi:https://doi.org/10. 5888/pcd 13.150567

21. Higgins TC, O'Malley AS, Keith RE. Exploring and Overcoming the Challenges Primary Care Practices Face with Care Management of HighRisk Patients in CPC+: a Mixed-Methods Study. J Gen Intern Med. 2021; doi:https://doi.org/10.1007/s11606-020-06528-0

22. Auerbach AD, Kripalani S, Vasilevskis EE, et al. Preventability and Causes of Readmissions in a National Cohort of General Medicine Patients. JAMA Intern Med. 2016;176(4):484-93. doi:https://doi.org/10. 1001/jamainternmed.2015.7863

23. Feigenbaum $\mathbf{P}$, Neuwirth $\mathbf{E}$, Trowbridge $\mathbf{L}$, et al. Factors contributing to all-cause 30-day readmissions: a structured case series across 18 hospitals. Med Care. 2012;50(7):599-605. doi:https://doi.org/10.1097/ MLR.Ob013e318249ce72

24. Patel KK, Vakharia N, Pile J, Howell EH, Rothberg MB. Preventable Admissions on a General Medicine Service: Prevalence, Causes and Comparison with AHRQ Prevention Quality Indicators-A Cross-Sectional Analysis. J Gen Intern Med. 2016;31(6):597-601. doi:https://doi.org/10. 1007/s11606-016-3615-4

25. Coulter A. Patient engagement-what works? J Ambul Care Manage. 2012;35(2):80-9. doi:https://doi.org/10.1097/JAC.0b013e318249e0fd

26. Zulman DM, O'Brien CW, Slightam C, Breland JY, Krauth D, Nevedal AL. Engaging High-Need Patients in Intensive Outpatient Programs: A Qualitative Synthesis of Engagement Strategies. J Gen Intern Med. 2018;33(11):1937-1944. doi:https://doi.org/10.1007/ s11606-018-4608-2

27. Madden EF, Kalishman S, Zurawski A, O'Sullivan P, Arora S, Komaromy M. Strategies Used by Interprofessional Teams to Counter Healthcare Marginalization and Engage Complex Patients. Qual Health Res. 2020;30(7):1058-1071. doi:https://doi.org/10.1177/ 1049732320909100

28. Wray CM, Vali M, Byers A, Keyhani S. Examining the Association of Social Determinants of Health with Missed Clinic Visits in Patients with Heart Failure in the Veterans Health Administration. $J$ Gen Intern Med. 2020;35(5):1591-1592. doi:https://doi.org/10.1007/ s11606-019-05507-4

29. Wong MS, Luger TM, Katz ML, et al. Outcomes that Matter: High-Needs Patients' and Primary Care Leaders' Perspectives on an Intensive Primary Care Pilot. J Gen Intern Med. 2021;doi:https://doi.org/10.1007/ s11606-021-06869-4

30. Flaks-Manov N, Srulovici E, Yahalom R, Perry-Mezre H, Balicer R, Shadmi E. Preventing Hospital Readmissions: Healthcare Providers' Perspectives on "Impactibility" Beyond EHR 30-Day Readmission Risk Prediction. J Gen Intern Med. 2020;35(5): 1484-1489. doi:https://doi.org/ 10.1007/s11606-020-05739-9

31. Katz MH. Trust but Verify (Ideally With a Randomized Clinical Trial). JAMA Internal Medicine. 2017;177(2):162-163. doi:https://doi.org/10. 1001/jamainternmed.2016.8433

32. Jonas W, Schoomaker E, Marzolf J, Gaudet T. Finding the Cause of the Crises: Opioids, Pain, Suicide, Obesity, and Other \&\#x201c; Epidemics\&\#x201d. Catalyst Carryover. 2019;5(3)doi:https://doi.org/ 10.1056/CAT. 19.0662

33. Rosland AM, Nelson $\mathbf{K}$, Sun $\mathbf{H}$, et al. The patient-centered medical home in the Veterans Health Administration. Am J Manag Care. 2013;19(7): e263-72.

34. Greene SM, Reid RJ, Larson EB. Implementing the learning health system: from concept to action. Ann Intern Med. 2012;157(3):207-10. doi: https://doi.org/10.7326/0003-4819-157-3-201208070-00012

Publisher's Note: Springer Nature remains neutral with regard to jurisdictional claims in published maps and institutional affiliations. 